\title{
Closed Incision Negative Pressure Therapy: Review of the Literature
}

\author{
Luis G. Fernandez ${ }^{1}$, Marc R. Matthews ${ }^{2}$, Pablo Sibaja Alvarez ${ }^{3}$, Scott Norwood ${ }^{4}$, David H. Villarreal ${ }^{5}$ \\ 1. Surgery, Trauma Wound Care, University of Texas Health Science Center, Tyler, USA 2. Surgery, Arizona Burn Center, \\ Phoenix, USA 3. General Surgery, Universidad Federada San Judas Tadeo, San Jose, CRI 4. Surgery, University of Texas \\ Health Science Center, Tyler, USA 5. Trauma, Acute Care Surgery, Surgical Critical Care, University of Texas Health \\ Science Center, Tyler, USA
}

Corresponding author: Luis G. Fernandez, thebigkahuna115@gmail.com

\begin{abstract}
Surgical site infection and other common surgical site complications (dehiscence, hematoma, and seroma formation) can lead to serious and often life-threatening complications. Gauze, adhesive dressings, and skin adhesives have traditionally been utilized for incision management. However, the application of negative pressure wound therapy over clean, closed surgical incisions (closed incision negative pressure therapy, ciNPT), has become a recent option for incision management. A brief review of ciNPT clinical evidence and health economic evidence are presented. A brief literature review was performed using available publication databases (PubMed, Ovid ${ }^{\circledR}$, Embase ${ }^{\circledR}$, and QUOSA ${ }^{\mathrm{TM}}$ ) for articles in English reporting on the use of ciNPT between October 1, 2016, to March 31, 2019. The successful application of ciNPT over clean, closed wounds has been reported in a broad spectrum of patients and operative interventions, resulting in favorable clinical results. Four of the five studies that examined health economics following the use of ciNPT reported a potential reduction in the cost of care. The authors' own experience and published results suggest that patients at high risk for developing a surgical site complication may benefit from the use of ciNPT during the immediate postoperative period. Additional studies are needed across various surgical disciplines to further assess the safety, and cost-effectiveness of ciNPT use in patient populations.
\end{abstract}

Categories: Plastic Surgery, General Surgery

Keywords: closed incision negative pressure therapy, literature reviews, health economics

\section{Introduction And Background}

Surgical site infections (SSIs) and other common surgical site complications (dehiscence, hematoma, and seroma formation) can lead to serious and often life-threatening complications. Recent reports suggest that there are 8.2 million people at risk for SSIs annually in the United States [1-3]. SSIs frequently occur and are now the most common and costly of all healthcare-acquired infections, with a reported incidence ranging from $15-37 \%$ [4-7]; and accounts for $33.7 \%$ of the $\$ 9.8$ billion costs to the US healthcare system per year [1].

Received 06/07/2019

Review began 06/18/2019 Review ended 07/10/2019 Published 07/21/2019

๑) Copyright 2019

Fernandez et al. This is an open access article distributed under the terms of the Creative Commons Attribution License CC-BY 3.0., which permits unrestricted use, distribution, and reproduction in any medium, provided the original author and source are credited.
Standard of care (SOC) therapy typically consists of dry or moistened gauze, abdominal pads, adhesive dressings, or skin adhesives. However, gauze dressings have been criticized for their inherent nonocclusive nature [8] and associated with a higher infection rate than transparent films or hydrocolloids [9, 10]. A more recent option for surgical incision management, especially in patients at high risk of developing surgical site complications, is the use of closed incision negative pressure (ciNPT). A brief literature search is presented.

\section{Review}

\section{Methods}

Literature Search

A literature search was performed using available publication databases (PubMed, Ovid ${ }^{\circledR}$, Embase ${ }^{\circledR}$, and QUOSA $^{\mathrm{TM}}$ ) for peer-reviewed articles published between October 1, 2016, and March 31, 2019. Keywords included "Prevena”, "NPT" (negative pressure therapy), "Negative wound therapy", and "negative pressure therapy”. Literature inclusion and exclusion criteria are listed in Table 1. 


\section{Cureus}

\begin{tabular}{|l|l|}
\hline Inclusion Criteria & Exclusion Criteria \\
\hline Use of ciNPT & Abstract \\
\hline English language & Review Article \\
Study population $>1$ & Meta-analysis \\
& Single case reports \\
& Non-English article \\
& Veterinary study \\
& Non-clinical reports \\
& Pre-clinical studies \\
& Use of non-ciNPT device \\
\hline
\end{tabular}

\section{TABLE 1: Literature search inclusion and exclusion criteria}

ciNPT- closed incision negative pressure therapy (PREVENA ${ }^{\mathrm{TM}}$ Incision Management System, $\mathrm{KCl}$, an ACELITY Company, San Antonio, US)

\section{Results}

Literature Search

A total of 88 articles were identified during the literature search. Once duplicates and articles not meeting the inclusion criteria were removed, 40 articles were identified. Of these included articles, 12 were randomized controlled trials (RCTs), six were prospective cohort studies, 15 were retrospective comparative studies, and seven were case series.

The successful application of ciNPT on clean, closed wounds has been reported in a broad spectrum of patients and operative interventions resulting in positive clinical results in a majority of the RCTs identified in the literature search (Table 2) [11-19]. Similarly, rates of SSIs, surgical site complications, readmissions, and/or reoperations were reduced in patients receiving ciNPT compared to historical control populations [20-25].

\begin{tabular}{|c|c|c|}
\hline Author & $\begin{array}{l}\text { Patient } \\
\text { Population }\end{array}$ & Results \\
\hline $\begin{array}{l}\text { Engelhardt } \\
\text { et al. [26] }\end{array}$ & $\begin{array}{l}132 \text { patients } \\
\text { Vascular } \\
\text { surgery ciNPT, } \\
\mathrm{n}=64 ;{ }^{*} \text { Control, } \\
\mathrm{n}=68\end{array}$ & $\begin{array}{l}\text { Infection rates slightly lower in ciNPT patients }(9 / 64 \text { ciNPT vs } 19 / 68 \text { control; } p=0.055) \text {. Early infection rates were } \\
\text { similar between the two groups ( } 4 / 64 \text { ciNPT vs } 10 / 68 \text { control; } p=0.125) \text {. }\end{array}$ \\
\hline $\begin{array}{l}\text { Gombert } \\
\text { et al. [11] }\end{array}$ & $\begin{array}{l}204 \text { patients } \\
\text { Vascular } \\
\text { surgery ciNPT, } \\
\mathrm{n}=98 ;{ }^{*} \text { Control, } \\
\mathrm{n}=90\end{array}$ & Significantly lower levels of SSI in ciNPT group (13/98 vs 30/90 control; $p=0.0015)$. \\
\hline $\begin{array}{l}\text { Gunatilake } \\
\text { et al. [12] }\end{array}$ & $\begin{array}{l}82 \text { patients } \\
\text { Cesarean } \\
\text { delivery ciNPT, } \\
\mathrm{n}=39 ;{ }^{*} \text { Control, } \\
\mathrm{n}=43\end{array}$ & $\begin{array}{l}\text { Reduced surgical site occurrences in ciNPT group }(2 / 39 \text { vs } 7 / 43 ; p=0.16) \text {. Significantly reduced pain at rest }(29 / 39 \\
\text { vs } 39 / 43, p<0.01) \text {. Significantly reduced pain with pressure in ciNPT group }(25 / 39 \text { vs } 42 / 43, p<0.001) \text {. Significantly } \\
\text { reduced total narcotic use in ciNPT group ( } 55.9 \% \text { vs } 79.1 \%, p=0.036) \text {. Similar rates of acetaminophen use in both } \\
\text { groups }(p=0.47) \text {. Similar rates of total NSAID use in both groups }(p=0.87) \text {. }\end{array}$ \\
\hline $\begin{array}{l}\text { Javed et } \\
\text { al. [13] }\end{array}$ & $\begin{array}{l}123 \text { patients } \\
\text { Abdominal } \\
\text { surgery ciNPT, } \\
\mathrm{n}=62 ;{ }^{*} \text { Control, } \\
\mathrm{n}=61\end{array}$ & $\begin{array}{l}\text { Reduced SSI in ciNPT group }(9.7 \%) \text { vs control group }(31.1 \%, \mathrm{RR}=0.31,95 \% \mathrm{CI} 0.13-0.73 ; \mathrm{p}=0.03) \text {. Reduced rate } \\
\text { of superficial SSI in ciNPT group }(6.5 \%) \text { vs control group }(27.9 \% ; \mathrm{p}=0.002) \text {. Similar rate of deep SSI in both groups } \\
\text { (3.2\% vs } 3.3 \% ; \mathrm{p}=0.99) \text {. Similar lengths of stay in the ICU ( } 1 \text { day vs } 1 \text { day) and hospital }(7 \text { days vs } 8 \text { days) for both } \\
\text { groups ( } p>0.05) \text {. Similar rates of reoperation for ciNPT and control groups }(1.6 \% \text { vs } 6.6 \% ; p=0.21) \text {. Reduced rates } \\
\text { of readmission for ciNPT group, though not statistically significant. }(8.1 \% \text { vs } 19.7 \% ; p=0.07) \text { Similar rates for } \\
\text { readmission for SSI between both groups ( } 4.8 \text { vs } 9.8 ; p=0.32) \text {. }\end{array}$ \\
\hline
\end{tabular}




\section{Cureus}

119 incisions

Vascular

Kwon et surgery ciNPT,

al. [14]

$\mathrm{n}=59$; * Control,

$\mathrm{n}=60$

60 patients

Cardiac

[15] surgery ciNPT, $\mathrm{n}=33$; *Control, $\mathrm{n}=27$

\section{2 patients}

surgery ciNPT,

Reduced SSI rates in ciNPT group ( $11 \%$ vs $19 \%$ control; $p=0.24)$ Significantly shorter length of stay in ciNPT group

[16]

\section{$\mathrm{n}=53$; ${ }^{*}$ Control,}

$n=49$

51 patients

Breast

Muller-

Sloof et al reconstruction

surgery ciNPT, $\mathrm{n}=25$; *Control,

$\mathrm{n}=26$

284 patients

Colorectal

Murphy et surgery ciNPT,

al. [27]

$n=144$;

*Control,

$n=140$

160 patients

Newman

et al. [18]

\section{Arthroplasty}

surgery ciNPT,

$\mathrm{n}=80$; *Control,

$\mathrm{n}=80$

100 patients,

129 incisions

Pleger et Vascular

surgery ciNPT,

$\mathrm{n}=58$ incisions;

*Control, $\mathrm{n}=71$

incisions

136 patients

Ruhstaller Cesarean

delivery ciNPT, Similar rates of wound complications were seen between both groups $(4.9 \%$ vs $6.9 \%$ control; $p=0.71)$.

$\mathrm{n}=67$; *Control,

$\mathrm{n}=69$
Reduced surgical site occurrences in high-risk ciNPT group (11.9\%) vs high-risk control group (26.7\%; $\mathrm{p}<0.01)$. Reduced reoperation rate in high-risk ciNPT group (8.5\%) vs high-risk control group (18.3\%; $p<0.05)$. Reduced readmission rate in high-risk ciNPT group $(6.8 \%)$ vs high-risk control group $(16.7 \% ; p<0.04)$. Similar length of stay in both high-risk groups (10.6 days for both).

Similar SSI rates in both groups ( $0 / 33$ vs $1 / 27$ control; $p>0.05)$. ciNPT was tolerated by patients. ciNPT group had a shorter length of stay ( 6 days vs 10 days control; $p=0.008$ ).

Reduced rates of surgical dehiscence in ciNPT group ( $8 \%$ vs $33 \% ; p=0.038)$. Similar rates of SSI between both groups $(4 \%$ vs $0 \% ; p>0.05)$.

Similar incidence of SSI at 30-days postoperatively between both groups (32\% ciNPT vs $34 \%$ control; $p=0.66$ ). Similar rates of reoperation between both groups ( $4 \%$ vs $4 \% ; p=0.96)$. Similar length of stay between both groups $(p=0.68)$.

Wound complication rate was significantly lower in ciNPT group ( $9 / 80$ vs $22 / 80$ control; $p=0.009$ ). Similar rates of readmission between the groups $(16 / 80$ vs $16 / 80 ; p=0.99)$. Reduced rates of reoperation in ciNPT group $(5 / 80$ vs $11 / 80 ; p=0.63$ ).

Significant reduction in wound complications in ciNPT group (5/58 vs $30 / 71$ control; $p<0.0005)$. Significant reduction in reoperation in ciNPT group $(1 / 58$ vs $10 / 71 ; p=0.022)$.

\section{TABLE 2: Randomized controlled trial evidence reporting the use of closed incision negative}

pressure therapy

*Control groups received traditional surgical dressings; ciNPT - closed incision negative pressure therapy; SSI - surgical site infection; RR - relative risk; $\mathrm{Cl}$ - confidence interval; NSAID - nonsteroidal anti-inflammatory drug

Economic Analysis of Published Clinical Studies

Only two studies identified from the literature search examined the economic impact of ciNPT use in patients at high risk for developing SSIs (Table 3) [14, 28]. The Kwon et al. study indicated a cost savings of $\$ 6,045$ in ciNPT patients; however, Ruhstaller et al. found an increase in patient costs $(\$ 10,300)$ in the ciNPT patient group [14, 28]. More economic studies are needed to fully assess the potential economic benefit of ciNPT use. 


\section{Cureus}

\begin{tabular}{|l|l|l|}
\hline Author & Patient Population & Results \\
\hline $\begin{array}{l}\text { Kwon et al. } \\
{[14]}\end{array}$ & $\begin{array}{l}119 \text { incisions; vascular surgery } \\
\text { ciNPT, } n=59 \text { Control, } n=60\end{array}$ & $\begin{array}{l}\text { Cost for high-risk ciNPT group care was } \$ 6,045 \text { less than the high-risk control group, } \\
\text { though not statistically significant }(\mathrm{p}=0.11) .\end{array}$ \\
$\begin{array}{l}\text { Ruhstaller } \\
\text { et al. }[28]\end{array}$ & $\begin{array}{l}136 \text { patients; Cesarean delivery } \\
\text { ciNPT, } n=67 \text { Control, } n=69\end{array}$ & $\begin{array}{l}\text { The prevention of one SSI would increase patient costs an average of } \$ 10,300 \text { (US). } 28 \\
\text { ciNPT would need to be placed to prevent one SSI. }\end{array}$ \\
\hline
\end{tabular}

\section{TABLE 3: Economic evidence in the use of closed incision negative pressure therapy}

ciNPT - closed incision negative pressure therapy

Patient Selection

The potential clinical value of ciNPT over clean, closed surgical incisions in a variety of patients at risk for developing surgical site complications has been shown in a growing body of literature. A review the RCT literature reports that patients that benefit most from ciNPT use were those at greater risk for infection, seroma, hematoma, and dehiscence [14-16, 18, 19]. These patients were found to have one or more risk factors that negatively affected wound healing and were undergoing high-risk surgical procedures. Stannard and associates have proposed the use of a Patient Grading System, which may be helpful in identifying candidates for ciNPT use (Table 4) [29]. Known patient risk factors or comorbidities include diabetes, obesity, smoking, hypertension, steroid use, radiation exposure, and other factors affecting wound healing (Table 5) $[30,31]$. Patients without pre-existing medical conditions may not be candidates for the ciNPT use as their surgical incisions usually heal well on their own [31, 32].

\begin{tabular}{|l|l|}
\hline Patient Risk Factors & Description \\
\hline Otherwise healthy, no pre-existing medical conditions & No risk factors \\
\hline Presence of a known risk factor* & Single risk factor \\
\hline Presence of multiple known risk factors & Multiple risk factors \\
\hline & Grade 1 \\
\hline TABLE 4: Patient grading system & Grade 3 \\
\hline *Known risk factors includes diabetes, obesity, tobacco use, hypertension, steroid use, radiation therapy, chemotherapy, and peripheral arterial \\
disease. Adapted from Stannard et al. [29].
\end{tabular}




\section{Cureus}

\begin{tabular}{|c|c|}
\hline Patient Risk Factors & Wound Risk Factors \\
\hline Age $>65$ & Wound infection \\
\hline Pulmonary disease & Length and depth of incision \\
\hline Vascular disease & Foreign body in the wound \\
\hline Hemodynamic instability & Type of injury \\
\hline \multicolumn{2}{|l|}{ Ostomies } \\
\hline \multicolumn{2}{|l|}{ Hypoalbuminemia } \\
\hline \multicolumn{2}{|l|}{ Systemic infection } \\
\hline \multicolumn{2}{|l|}{ Obesity } \\
\hline \multicolumn{2}{|l|}{ Hyperalimentation } \\
\hline \multicolumn{2}{|l|}{ Ascites } \\
\hline \multicolumn{2}{|l|}{ Malignancy } \\
\hline \multicolumn{2}{|l|}{ Hypertension } \\
\hline \multicolumn{2}{|l|}{ Anemia } \\
\hline \multicolumn{2}{|l|}{ Jaundice } \\
\hline \multicolumn{2}{|l|}{ Diabetes (poor control) } \\
\hline \multicolumn{2}{|l|}{ Active tobacco use } \\
\hline \multicolumn{2}{|l|}{ Radiation therapy } \\
\hline Steroid use & \\
\hline
\end{tabular}

\section{TABLE 5: Patient risk factors for incision complications}

Adapted from Riou et al. [30] and Abbas et al. [31].

\section{Discussion}

SSIs and other common surgical site complications (dehiscence, hematoma, and seroma formation) can lead to serious and often life-threatening complications. Traditional postoperative incision management has included gauze dressings, adhesive dressings, and skin adhesives; however, ciNPT can offer healthcare providers another incision management option.

A growing body of evidence has reported reduced rates of SSI and other surgical site complications resulting from ciNPT usage. The literature search identified 12 RCTs, a majority of which reported reduced SSI rates, reduced readmission rates, and reduced reoperation rates. Six of the non-RCT, comparative studies identified also reported reduced rates of SSIs, readmissions, and reoperations [20-25]. However, these studies examined a wide range of patients, with a variety of comorbidities, undergoing different surgical procedures. Thus, a definitive conclusion on the potential clinical benefit of ciNPT for specific patient groups or surgical procedure cannot be made with this literature search. Future meta-analyses limited to specific patient groups and surgical procedures are necessary.

Health economic data for ciNPT use is limited. While only two studies were identified in the literature search, they provided differing conclusions [14, 28]. Additionally, since 2009, only three other studies examining the health economics of ciNPT use have been published [33-35]. Chopra et al. [33] report that in their 829 patients undergoing abdominal wall reconstruction, ciNPT use resulted in an estimated cost savings of $\$ 1,542.52$ and could be a cost-effective option when the estimated SSI rate is above $16 \%$ for the patient population. Similarly, Grauhan et al. [34] reported an estimated cost savings of 60,000,000€ to $90,000,000 €$ per year in Germany for patients undergoing cardiac surgery. Matatov and colleagues [35] noted that for their vascular surgery patients, none required an extended hospital stay or care for SSI, suggesting cost savings with ciNPT use compared to the $>\$ 45,000$ costs for infection care and extended hospital stay for two control patients with Szilagyi grade III infection. Despite these additional studies, the health economic analysis of ciNPT use requires further research as the current body of literature is too limited to provide a definitive conclusion. 
This review is not without limitations. The review presented is not a systematic meta-analysis, but a literature review including both RCTs and observational studies and a variety of patient subgroups and surgical types. A number of meta-analyses have been published in recent years with results in favor of ciNPT use; however, they do not list patient use selection recommendations which we believe is beneficial for healthcare providers considering adding ciNPT to their patient treatment plans. As this review included a variety of patients and surgical procedures, additional patient subset or surgical type-specific meta-analyses are necessary to draw conclusions on the clinical effectiveness of ciNPT use. Additionally, health economic data regarding ciNPT use is limited. More research is needed as current data is too limited to provide a definitive conclusion.

\section{Conclusions}

The published literature suggests that patients at high risk for developing a surgical site complication may benefit ciNPT during the immediate postoperative period. Additional studies are needed across various surgical disciplines to further assess the safety, and cost-effectiveness of ciNPT use in patient populations.

\section{Additional Information}

\section{Disclosures}

Conflicts of interest: In compliance with the ICMJE uniform disclosure form, all authors declare the following: Payment/services info: LG Fernández and P Sibaja Alvarez are consultants for KCI, an ACELITY Company. MR Matthews is a surgical consultant and is on the Speakers Bureau of Steadmed/Urgo and KCI, an ACELITY Company. Financial relationships: L Fernandez, M Matthews, and P Sibaja Alvarez declare(s) personal fees from KCI, an ACELITY Company. LG Fernández, MR Matthews, P Sibaja Alvarez are consultants for KCI, an ACELITY Company. M Matthews declare(s) personal fees from Steadmed/Urgo. M Mathews is a surgical consultant and is on the Speakers Bureau of Steadmed/Urgo. Other relationships: All authors have declared that there are no other relationships or activities that could appear to have influenced the submitted work.

\section{Acknowledgements}

The author thanks Julie M. Robertson, $\mathrm{PhD}$ (Acelity) for assistance with manuscript preparation and editing.

\section{References}

1. Zimlichman E, Henderson D, Tamir O, et al.: Health care-associated infections: a meta-analysis of costs and financial impact on the US health care system. JAMA Intern Med. 2013, 173:2039-2046. 10.1001/jamainternmed.2013.9763

2. de Lissovoy G, Fraeman K, Hutchins V, Murphy D, Song D, Vaughn BB: Surgical site infection: incidence and impact on hospital utilization and treatment costs. Am J Infect Control. 2009, 37:387-397. 10.1016/j.ajic.2008.12.010

3. Urban JA: Cost analysis of surgical site infections. Surgical Infect (Larchmt). 2006, 7:S19-S22. 10.1089/sur.2006.7.s1-19

4. Watanabe A, Kohnoe S, Shimabukuro R, et al.: Risk factors associated with surgical site infection in upper and lower gastrointestinal surgery. Surg Today. 2008, 38:404-412. 10.1007/s00595-007-3637-y

5. Anderson DJ, Podgorny K, Berrios-Torres SI, et al.: Strategies to prevent surgical site infections in acute care hospitals: 2014 update. Infect Control Hosp Epidemiol. 2014, 35:605-627. 10.1086/676022

6. Ban KA, Minei JP, Laronga C, et al.: American college of surgeons and surgical infection society: surgical site infection guidelines, 2016 update. J Am Coll Surg. 2017, 224:59-74. 10.1016/j.jamcollsurg.2016.10.029

7. Magill SS, Edwards JR, Bamberg W, et al.: Multistate point-prevalence survey of health care-associated infections. N Engl J Med. 2014, 370:1198-1208. 10.1056/NEJMoa1306801

8. Lawrence JC: Dressings and wound infection. Am J Surg. 1994, 167:S21-S24. 10.1016/0002-9610(94)90006-X

9. Hutchinson JJ, Lawrence JC: Wound infection under occlusive dressings. J Hosp Infect. 1991, 17:83-94. 10.1016/0195-6701(91)90172-5

10. Sood A, Granick MS, Tomaselli NL: Wound dressings and comparative effectiveness data. Adv Wound Care. 2014, 3:511-529. 10.1089/wound.2012.0401

11. Gombert A, Babilon M, Barbati M, et al.: Closed incision negative pressure therapy reduces surgical site infections in vascular surgery: a prospective randomised trial (AIMS trial). Eur J Vasc Endovasc Surg. 2018, 56:442-448. 10.1016/j.ejvs.2018.05.018

12. Gunatilake RP, Swamy GK, Brancazio LR, et al.: Closed-incision negative-pressure therapy in obese patients undergoing cesarean delivery: a randomized controlled trial. AJP Rep. 2017, 7:151-157. 10.1055/s-00371603956

13. Javed AA, Teinor J, Wright M, et al.: Negative pressure wound therapy for surgical-site infections: a randomized trial. Ann Surg. 2019, 269:1034-1040. 10.1097/SLA.0000000000003056

14. Kwon J, Staley C, McCullough M, et al.: A randomized clinical trial evaluating negative pressure therapy to decrease vascular groin incision complications. J Vasc Surg. 2018, 68:1744-1752. 10.1016/j.jvs.2018.05.224

15. Lee AJ, Sheppard CE, Kent WD, Mewhort H, Sikdar KC, Fedak PW: Safety and efficacy of prophylactic negative pressure wound therapy following open saphenous vein harvest in cardiac surgery: a feasibility study. Interact Cardiovasc Thorac Surg. 2017, 24:324-328. 10.1093/icvts/ivw400 
16. Lee K, Murphy PB, Ingves MV, et al.: Randomized clinical trial of negative pressure wound therapy for highrisk groin wounds in lower extremity revascularization. J Vasc Surg. 2017, 66:1814-1819. 10.1016/j.jvs.2017.06.084

17. Muller-Sloof E, de Laat HE, Hummelink SL, Peters JW, Ulrich DJ: The effect of postoperative closed incision negative pressure therapy on the incidence of donor site wound dehiscence in breast reconstruction patients: dehiscence prevention study (DEPRES), pilot randomized controlled trial. J Tissue Viability. 2018, 27:262-266. 10.1016/j.jtv.2018.08.005

18. Newman JM, Siqueira MB, Klika AK, Molloy RM, Barsoum Wk, Higuera CA: Use of closed incisional negative pressure wound therapy after revision total hip and knee arthroplasty in patients at high risk for infection: a prospective, randomized clinical trial. J Arthroplasty. 2019, 34:554-559. 10.1016/j.arth.2018.11.017

19. Pleger SP, Nink N, Elzien M, Kunold A, Koshty A, Boning A: Reduction of groin wound complications in vascular surgery patients using closed incision negative pressure therapy (ciNPT): a prospective, randomised, single-institution study. Int Wound J. 2018, 15:75-83. 10.1111/iwj.12836

20. Gabriel A, Sigalove S, Sigalove N, Storm-Dickerson T, Rice J, Maxwell P, Griffin L: The impact of closed incision negative pressure therapy on postoperative breast reconstruction outcomes. Plast Reconstr Surg Glob Open. 2018, 6:e1880. 10.1097/GOX.0000000000001880

21. Cooper HJ, Roc GC, Bas MA, Berliner ZP, Hepinstall MS, Rodriguez JA, Weiner LS: Closed incision negative pressure therapy decreases complications after periprosthetic fracture surgery around the hip and knee. Injury. 2018, 49:386-391. 10.1016/j.injury.2017.11.010

22. Lo Torto F, Monfrecola A, Kaciulyte J, Ciudad P, Casella D, Ribuffo D, Carlesimo B: Preliminary result with incisional negative pressure wound therapy and pectoralis major muscle flap for median sternotomy wound infection in a high-risk patient population. Int Wound J. 2017, 14:1335-1339. 10.1111/iwj.12808

23. Redfern RE, Cameron-Ruetz C, O'Drobinak S, Chen J, Beer KJ: Closed incision negative pressure therapy effects on postoperative infection and surgical site complication after total hip and knee arthroplasty. J Arthroplasty. 2017, 32:3333-9. 10.1016/j.arth.2017.06.019

24. Schurtz E, Differding J, Jacobson E, Maki C, Ahmeti M: Evaluation of negative pressure wound therapy to closed laparotomy incisions in acute care surgery. Am J Surg. 2018, 215:113-5. 10.1016/j.amjsurg.2017.08.009

25. Zaidi A, El-Masry S: Closed incision negative pressure therapy in high-risk general surgery patients following laparotomy: a retrospective study. Colorectal Disease. 2017, 19:283-287. 10.1111/codi.13458

26. Engelhardt M, Rashad NA, Willy C, Muller C, Bauer C, Debus S, Beck T: Closed-incision negative pressure therapy to reduce groin wound infections in vascular surgery: a randomised controlled trial. Int Wound J. 2018, 15:327-332. 10.1111/iwj.12848

27. Murphy PB, Knowles S, Chadi SA, Vogt K, Brackstone M, Koughnett JAV, Ott MC: Negative pressure wound therapy use to decrease surgical nosocomial events in colorectal resections (NEPTUNE): a randomized controlled trial. Ann Surg. 2019, 270:38-42. 10.1097/SLA.0000000000003111

28. Ruhstaller K, Downes KL, Chandrasekaran S, Srinivas S, Durnwald C: Prophylactic wound vacuum therapy after cesarean section to prevent wound complications in the obese population: a randomized controlled trial (the provac study). Am J Perinatol. 2017, 34:1125-1130. 10.1055/s-0037-1604161

29. Stannard JP, Atkins BZ, O'Malley D, et al.: Use of negative pressure therapy on closed surgical incisions: a case series. Ostomy Wound Manage. 2009, 55:58-66.

30. Riou JP, Cohen JR, Johnson H Jr: Factors influencing wound dehiscence. Am J Surg. 1992, 163:324-330. 10.1016/0002-9610(92)90014-I

31. Abbas SM, Hill AG: Smoking is a major risk factor for wound dehiscence after midline abdominal incision; case-control study. ANZ J Surg. 2009, 79:247-250. 10.1111/j.1445-2197.2009.04854.x

32. Wilson JA, Clark JJ: Obesity: impediment to postsurgical wound healing. Adv Skin Wound Care. 2004, 17:426-435.

33. Chopra K, Gowda AU, Morrow C, Holton L, Singh DP: The economic impact of closed-incision negativepressure therapy in high-risk abdominal incisions: a cost-utility analysis. Plast Reconstr Surg. 2016, 137:1284-1289. 10.1097/PRS.0000000000002024

34. Grauhan O, Navasardyan A, Tutkun B, Henning F, Muller P, Hummel M, Hetzer R: Effect of surgical incision management on wound infections in a poststernotomy patient population. Int Wound J. 2014, 11:6-9. 10.1111/iwj.12294

35. Matatov T, Reddy KN, Doucet LD, Zhao CX, Zhang WW: Experience with a new negative pressure incision management system in prevention of groin wound infection in vascular surgery patients. J Vasc Surg. 2013, 57:791-795. 10.1016/j.jvs.2012.09.037 